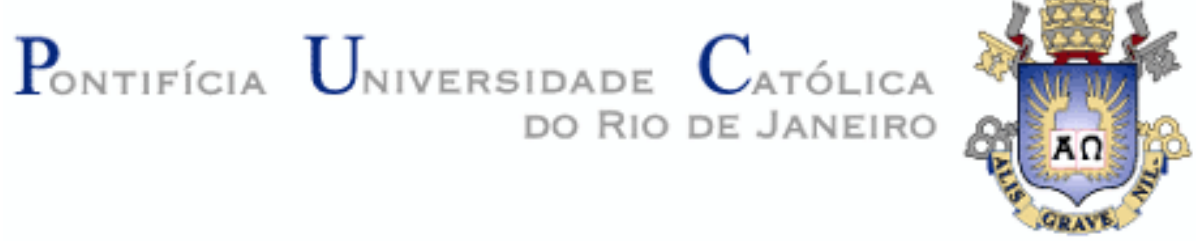

João Cícero Teixeira Bezerra

\title{
O Renascimento de Giulio Carlo Argan: \\ um estudo sobre o espaço
}

Tese apresentada como requisito parcial para obtenção do grau de Doutor pelo Programa de Pós-Graduação em História Social da Cultura do Departamento de História do Centro de Ciências Sociais da PUC-Rio.

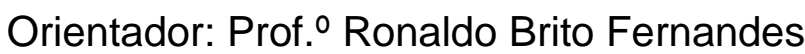


João Cícero Teixeira Bezerra

\section{O Renascimento de Giulio Carlo Argan: um estudo sobre o espaço}

Tese apresentada como requisito parcial para obtenção do grau de Doutor pelo Programa de Pós-Graduação em História Social da Cultura do Departamento de História do Centro de Ciências Sociais da PUC-Rio.

Aprovada pela Comissão Examinadora abaixo assinada.

\section{Prof. Ronaldo Brito Fernandes} Orientador

Departamento de História - PUC-Rio

Profa Sônia Salzstein Goldberg

Escola de Comunicação e Artes Departamento de Artes Plásticas - USP

Prof ${ }^{a}$ Vera Beatriz Cordeiro Siqueira Instituto de Artes - UERJ

Prof. José Thomaz Almeida Brum Duarte História da Arte e Arquitetura no Brasil/CCE-PUC-Rio

Prof ${ }^{\mathrm{a}}$ Flávia Maria Schlee Eyler

Departamento de História - PUC-Rio

Profạ. Mônica Herz

Vice-Decana de Pós-Graduação do Centro de Ciências Sociais

PUC-Rio

Rio de Janeiro, 14 de abril de 2015 
Todos os direitos reservados. É proibida a reprodução total ou parcial do trabalho sem autorização do autor, do orientador e da universidade.

\section{João Cícero Teixeira Bezerra}

Bacharelou-se em Artes Cênicas-Teoria do Teatro pela Universidade Federal do Estado do Rio de Janeiro - UNIRIO (2007). Obteve o grau de Mestre em Artes Cênicas pela UNIRIO (2009). Obteve o grau de Doutor em História pela PUCRio (2015). Professor da Faculdade de Design de Moda do Senai-Cetiqt (2008-2015). Concluiu o Doutorado em História Social da Cultura - PUCRio (2015).

Ficha Catalográfica

Bezerra, João Cícero Teixeira

O Renascimento de Giulio Carlo Argan: um estudo sobre o espaço / João Cícero Teixeira Bezerra ; orientador: Ronaldo Brito Fernandes $-2015$.

267 f. : il. (color.) ; $30 \mathrm{~cm}$

Tese (doutorado)-Pontifícia Universidade Católica do Rio de Janeiro, Departamento de História, 2015.

1. História - Teses. 2. Historiografia. 3. Estética. 4. Renascimento. I. Fernandes, Ronaldo Brito. II. Pontifícia Universidade Católica do Rio de Janeiro. Departamento de História. III. Título.

CDD: 900 


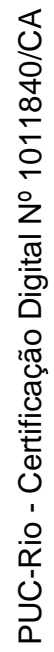

Para Maria Flora Süssekind e Maria de Lourdes Rabetti, Pelo amor a Crítica e a História. 


\section{Agradecimentos}

Ao professor Ronaldo Brito, pela orientação, e por suas aulas sempre inquietantes e valiosas. Com admiração por seu pensamento.

Agradeço à professora Maria de Lourdes Rabetti, por sua presença na minha formação intelectual de historiador da arte e do teatro. Com admiração por seu rigor acadêmico.

À professora Flora Süssekind, por sua amizade, afeto e contribuição a minha formação intelectual e crítica.

À professora Cecília Cotrim, por sua contribuição para o meu desenvolvimento neste programa de História Social da Cultura.

À professora Flavia Eyler, por suas contribuições valiosas a este trabalho no exame de qualificação, seu forte incentivo no término do doutorado.

Ao amigo Danrlei, por suas contribuições valiosas a este trabalho no exame de qualificação.

Ao professor Ricardo Benzaquen, por suas aulas dotadas de grande erudição e reflexão. Com admiração por seu pensamento.

À Edna Timbó, por seu cuidado. Obrigado pela paciência.

Agradeço também aos professores Thomas Brum, Sonia Salzstein, Vera Beatriz Siqueira que aceitaram fazer parte desta banca de doutorado de um admirador desconhecido.

À Martha Telles, que além de suplente da banca, é uma amiga muito especial. Não teria palavras para expressar a minha gratidão.

Aos meus amigos librianos queridos, João Dalla Rosa e Manoel Friques. Sem o companheirismo e a troca intelectual dos dois a vida não teria sentido.

Ao Bruno Ennes, com afeto. Obrigado por participar desta pesquisa. Cada imagem e palavra desta tese passaram por uma troca e amadurecimento nosso.

Aos professores da Faculdade de Artes e Design do SENAI-CETIQT. Cito, em especial, os que tem estado próximos a mim: Glaucia, Luciana, Maria, Ana Paula, Joana, Claudinha, Gisela, Paola, Rosa Marly, Rosa Basin, Paloma.

Agradeço ao Pedro, por todo carinho mesmo depois da separação. 
Agradeço ao CNPq pela bolsa de estudos concedida.

Finalmente, faço um agradecimento especial a minha mãe. Obrigado por ter entendido a minha ausência neste momento final da tese, por ter orado por mim, e, apesar de toda a sua dificuldade de saúde e solidão interior, ter me dedicado um amor profundo. 


\section{Resumo}

Bezerra, João Cícero Teixeira; Fernandes, Ronaldo Brito. O Renascimento de Giulio Carlo Argan: um estudo sobre o espaço. Rio de Janeiro, 2015, 267 p. Tese de Doutorado - Departamento de História, Pontifícia Universidade Católica do Rio de janeiro.

A tese discute a historiografia de Giulio Carlo Argan no contexto do Renascimento italiano, dando atenção à questão espacial que se coloca com a descoberta da perspectiva linear na construção da cúpula de Brunelleschi e nos afrescos de Masaccio, e também a reação a esta espacialidade em Fra Angelico e Sandro Botticelli. Para isto, analisam-se biografias artísticas erigidas pelo historiador italiano em que se debate a problemática do espaço e de sua historicidade, a fim de se compreender o nexo ético e histórico construído por ele entre o Renascimento italiano e a arte moderna, cotejando suas referências teóricas, filosóficas em contraste com outros projetos historiográficos que revisitaram o período a partir de um outro prisma, como é o caso de Erwin Panofsky, George Didi-Huberman, Fredric Antal, Jacob Burckhardt, Aby Warburg, entre outros.

\section{Palavras-Chave}

Historiografia; Estética; Renascimento. 


\section{Abstract}

Bezerra, João Cícero Teixeira; Fernandes, Ronaldo Brito. (Advisor) Giulio Carlo Argan's Renaissance: a study about space. Rio de Janeiro, 2015, 267 p. PhD. Thesis - Departamento de História, Universidade Católica do Rio de Janeiro.

The thesis discusses Giulio Carlo Argan's historiography in the context of the Italian Renaissance, focusing on the spatial question that begins with linear perspective's discovery in the construction of Brunelleschi's dome and the frescoes by Masaccio, and also the reaction to this spatiality in Fra Angelico and Sandro Botticelli. In this case, we analyze artistic biographies written by the italian author which debate the issue of space and its historicity, in order to comprehend the ethical and historical nexus built by him between the Italian Renaissance and modern art, checking their theoretical and philosophical references in contrast to other historiographical projects that revisited the period from different interpretations, as is the case of Erwin Panofsky, George DidiHuberman, Fredric Antal, Jacob Burckhardt, Aby Warburg, among others.

\section{Keywords}

Historiography, aesthetics, Renaissance. 


\section{Sumário}

1. Introdução: algumas perspectivas

2. A dimensão do trabalho na arte do Renascimento: o caso de Brunelleschi (1377-1446)

2.1. Biografia e teoria: Manetti e Alberti

2.2. Brunelleschi e Ghiberti: as disputas de "espaço(s)" no Renascimento

2.2.1. As formellas: narrativa e drama 31

2.2.2. A cúpula - o trabalho e a técnica 41

2.3. A perspectiva como forma simbólica e o significado da cúpula de Filippo Brunelleschi - Argan e Panofsky

2.3.1. A perspectiva e o símbolo

2.3.2. Argan e o significado da Cúpula

3. Masaccio (1401-1428): o passado (o retroceder a Giotto) e o presente (o aqui-agora com Brunelleschi)

3.1. O passado: Giotto 77

3.1.1. Giotto e o renascimento cultural latino

3.1.2. Giotto e a dimensão ético-religiosa

3.1.3. Giotto: pintura e desenho

3.2. O presente: o cruzamento da poética de Giotto e Brunelleschi em Masaccio

3.2.1. O crucifixo: a tradição e os dilemas da representação 96

3.2.2. A Adoração dos Magos: as versões 110

3.2.3. O Tributo: o espaço ético 120

4. Fra Angélico: o Renascimento como cristandade 134

4.1. Angelico e o Renascimento (espaço e cultura religiosa) 134

4.2. O outro Angelico: a leitura contemporânea de George

Didi-Huberman

4.2.1. A experiência inconsciente/ os limites da história e a ficção 147

4.2.2. A análise do afresco de Angelico 155

4.2.3. O visível, o invisível e o visual/ o virtual e o sintoma 163

5. Botticelli: a imagem e a forma 180

5.1. Introdução: a imagem e a forma 180

6. A imagem da história: um debate historiográfico sobre o tempo presente em Giulio Carlo Argan

7. Conclusão: o problema do universal 251

8. Referências Bibliográficas 258 


\section{Lista de ilustrações}

Ilustração 1: GHIBERTI, L. Sacrifício de Isaac. Bronze, 45 x $38 \mathrm{~cm}$.

Florença, Museu Nacional de Bargello

Ilustração 2: BRUNELLESCHI, F. Sacrifício de Isaac. Bronze, $45 \times 38 \mathrm{~cm}$. Florença, Museu Nacional do Bargello

Ilustração 3: GHIBERTI, L. Esaú e Jacó. Bronze dourado, 79 x 79 cm.

Florença, Batistério de San Giovanni, porta oeste

(Porta del Paradiso)

Ilustração 4: DONATELLO. Banquete de Herodes. Bronze dourado, $60 \times 60 \mathrm{~cm}$. Siena, Batistério

Ilustração 5: Igreja de Santa Maria del Fiore. Construção. Florença 72

Ilustração 6: GHIBERTI, L. Porta do Batistério. Florença, Batistério 73

llustração 7: NANNI di Banco. Porta da Mandorla. Florença, igreja de Santa Maria del Fiore.

Ilustração 8: GIOTTO. Campanário, Florença

Ilustração 9: BRUNELLESCHI, F. Cúpola da igreja de Santa Maria del Fiore, Florença

Ilustração 10: MONACO, L. Adoração dos Magos. Têmpera sobre madeira, $144 \times 177 \mathrm{~cm}$. Florença, Galeria dos Ufizzi

Ilustração 11: FABRIANO, G. Adoração dos Magos. Têmpera sobre madeira, $203 \times 282 \mathrm{~cm}$. Florença, Galeria dos Uffizi

Ilustração 12: MASACCIO. Adoração dos Magos. Têmpera sobre madeira, 21 x $61 \mathrm{~cm}$. Berlim, Staatliche Museen.

Ilustração 13: GIOTTO. São Francisco Alimentando os Pássaros. Afresco, $270 \times 200 \mathrm{~cm}$. Igreja de São Francisco de Assis

Ilustração 14: LORENZETTI, A. A Cidade sob os Efeitos do Bom Governo. Afresco. Siena, Palácio Público

Ilustração 15: GIOTTO. A Doação do Manto. Afresco, 270 x 230cm. Igreja de São Francisco de Assis

Ilustração 16: GIOTTO. Crucifixo. Têmpera sobre madeira, 578 x $406 \mathrm{~cm}$. Florença, Igreja de Santa Maria Novella

Ilustração 17: MASACCIO. Trindade. Afresco, 667 x $317 \mathrm{~cm}$. Florença, Igreja de Santa Maria Novella

Ilustração 18: KLIMT, G. Friso de Beethoven, 1902. Viena

Ilustração 19: ANGELICO. Deposição (Retábulo de Santa Trinita). Têmpera sobre madeira, 176 x $185 \mathrm{~cm}$. Florença, Museu de San Marco 
Ilustração 20: ANGELICO. Lamentação Sobre o Cristo Morto.

Têmpera e ouro sobre painel, 109 × 166 cm. Florença,

Museu de San Marco.

Ilustração 21: ANGELICO. Anunciação. Afresco, 176 x $148 \mathrm{~cm}$.

Florença, Museu de San Marco.

172

Ilustração 22: BOTTICELLI, S. Anunciação. Têmpera sobre madeira, 150 x $156 \mathrm{~cm}$. Florença, Galeia dos Uffizi

173

Ilustração 23: BOTTICELLI, S. Nascimento da Vênus. Têmpera sobre madeira, 172 × $278 \mathrm{~cm}$; Florença, Galeria dos Uffizi

174

Ilustração 24: Sandro Botticelli, Primavera; têmpera sobre madeira, 203 × $314 \mathrm{~cm}$; Florença, Galeria dos Uffizi

llustração 25: PIERO DELLA FRANCESCA. Anunciação. Afresco, 329 X 193cm. Arezzo, Basílica de São Francisco de Assis

Ilustração 26: ANGELICO. Virgem em trono com Menino, anjos, oito santos e crucifixo. Têmpera sobre madeira, $220 \times 227 \mathrm{~cm}$. Florença, Museu de San Marco

Ilustração 27: ANGELICO. Anunciação. Afresco, 230 × $321 \mathrm{~cm}$. Florença, Museu de San Marco

Ilustração 28: Interior do Convento São Marco. Fotografia

Ilustração 29: Janela ao lado do Afresco de Fra Angelico - Interior do Convento de São Marco. Fotografia

Ilustração 30: JUDD, D. Sem Título. 1980. Escultura

179

Ilustração 31: Autor Desconhecido. Vênus de Willendorf. (25.000 A.C) 203

Ilustração 32: WARHOL, A. Sem Título. 1967. Impressão em papel, $91 \times 91 \mathrm{~cm}$. Tate

204

Ilustração 33: GHIRLANDAIO, D. São Jerônimo. Afresco, 184 x 119 cm; Florença, Ognissanti

Ilustração 34: BOTTICELLI, S. Santo Agostinho. Afresco, 185 x $123 \mathrm{~cm}$. Florença, Ognissanti

Ilustração 35: SANZIO, R. Retrato de Baldassare Castiglione. Óleo sobre tela, $82 \times 67 \mathrm{~cm}$. Paris, Musée du Louvre

Ilustração 36: CONSTABLE, J. O Cavalo Branco. 1818-1819. Óleo sobre tela, Washington, National Gallery of Art, Widener Collection.

Ilustração 37: TURNER, W. Navio Negreiro. Óleo sobre tela. 1840.

Boston, Museum of Fine Arts 